\title{
Ectopic Banking and Implantation of an Amputated Hand
}

\author{
Omid Liaghat $^{1} \cdot$ Zohre Shabbooie $^{2}$
}

Received: 25 November 2019 / Accepted: 24 February 2020 / Published online: 18 March 2020

(c) The Author(s) 2020

\begin{abstract}
Background Ectopic banking includes techniques and indications used to bank amputated body parts for later replantation when a body part is amputated in its entirety. Immediate replantation is sometimes impossible due to hemodynamic instability, soft tissue loss, and extensive contamination of the amputated part. The first case of temporary ectopic banking of hand implantation was reported in 2015 by Xu Zhang in China which was not completely successful. The first replantation was reported almost 54 years ago, followed by a limited number of similar cases that were not successful. Xu could not restore the useful function of the replanted hand.

Purpose In this study, we reported a case of hand replantation by the banking technique.

Method We carried out a hand replantation by the banking technique using the right ankle as the recipient site.

Result We restored the useful function of the amputated part and evaluated the function with standard tests.

Conclusion Using right ankle as recipient site in ectopic banking can be a useful approach which helps and ensures the researchers and surgeons to decide if they intend to use this method.
\end{abstract}

Keywords Amputation $\cdot$ Hand $\cdot$ Ectopic banking $\cdot$ Implantation

\section{Introduction}

Ectopic banking, initially defined by Godina in 1986, includes techniques and indications used to bank amputated body parts for later replantation [1]. This method plays an important role in limb-saving and extremity salvage techniques, especially for hand surgeons who perform replantation surgeries [2]. When a body part is amputated in its entirety, immediate replantation is sometimes impossible due to hemodynamic instability, soft-tissue loss, and extensive contamination of the amputated part [3].

The first replantation was reported almost 54 years ago, followed by a limited number of similar cases that were not successful [3]. However, since 1986, reported cases of

Zohre Shabbooie

shabboogarden@yahoo.com

Omid Liaghat

oliaghat@yahoo.com

1 Shafa Yahyaian Hospital, Orthopedic Center, Iran University of Medical Sciences, Tehran, Iran

2 Department of Medical Journalism, Shiraz University of Medical Sciences, Room 25, 2nd Floor, Building No 1, Paramedical School, Meshkinfam st., Shiraz, Iran replantation via banking techniques included amputated hands, total upper extremities, digits, the feet, scalp, and penis [4-8]. In the first case, Zhang reported a temporary ectopic hand implantation in 2015 in China that was not successful [9].

In this case report, we describe our experience with hand replantation by the banking technique. The patient's right ankle was the recipient site.

\section{Case Report}

A 24 year old man sustained a complete right-dominant hand amputation in an accident by motorcycle, in February 11, 2017 at 9:00 PM.

Cold ischemia time was $5 \mathrm{~h}$ at arrival. Other organ examinations were normal. He was emergently transferred to operating room where fluoroscopic study was done.

About $7 \mathrm{~cm}$ of the distal radius and $5 \mathrm{~cm}$ of the distal ulna were missing. Amputated part included proximal carpal row. Both the amputated part and proximal stump were extremely contaminated. Soft tissues were evaluated. In amputated part, there was no other injury distal-to-amputation level. Flexor and extensor tendons were cut at wrist level. Radial 
artery was not usable, but ulnar artery had $3 \mathrm{~cm}$ healthy stump. Ulnar nerve was cut $3 \mathrm{~cm}$ proximal to wrist and had less longitudinal damage than median nerve which was cut at about the carpal bones. Proximal stump showed much more damage. Remained ulna was $2 \mathrm{~cm}$ longer than radius. Some flexor and extensor muscles and tendons seemed viable, especially at the ulnar side of forearm. Median nerve had more longitudinal damage than ulnar nerve. Proximal stump of radial and ulnar arteries was damaged up to $5 \mathrm{~m}$ proximal to radius amputation level.

Primary replantation was not feasible because of the extent of contamination and large vascular gap. We decided to preserve the amputated part, because it was almost not injured distal-to-amputation level (Figs. 1, 2).

After complete debridement of all visible foreign bodies and crushed soft tissues of the amputated part under magnification, right leg was selected for banking (see "Discussion"). The posterior tibia artery was isolated and the saphenous vein was harvested distally. A $7 \times 10 \mathrm{~cm}$ saphenous fasciocutaneous flap was created and elevated to provide temporary coverage. Then, end-to-end ulnar artery anastomosis was done to the posterior tibia artery. After venous blood clearance, main dorsal vein was anastomosed to saphenous vein. All other arteries and veins were ligated. Coverage was done by saphenous flap. Proximal forearm stump was then debrided under magnification. Both bones were shortened about $1 \mathrm{~cm}$ (Fig. 3).

Aspirin $320 \mathrm{mg} / \mathrm{day}$, antibiotics and wound treatment, three times daily was started after operation.

Two operative sessions of debridement were performed 3 and 5 days after banking to prepare the proximal stump for final transfer (Fig. 4).

On the 8th day, banked wrist was harvested with $15 \mathrm{~cm}$ posterior tibia artery and $35 \mathrm{~cm}$ saphenous vein pedicles (Figs. 5, 6, 7, 8). Because the radius was shorter than ulna,
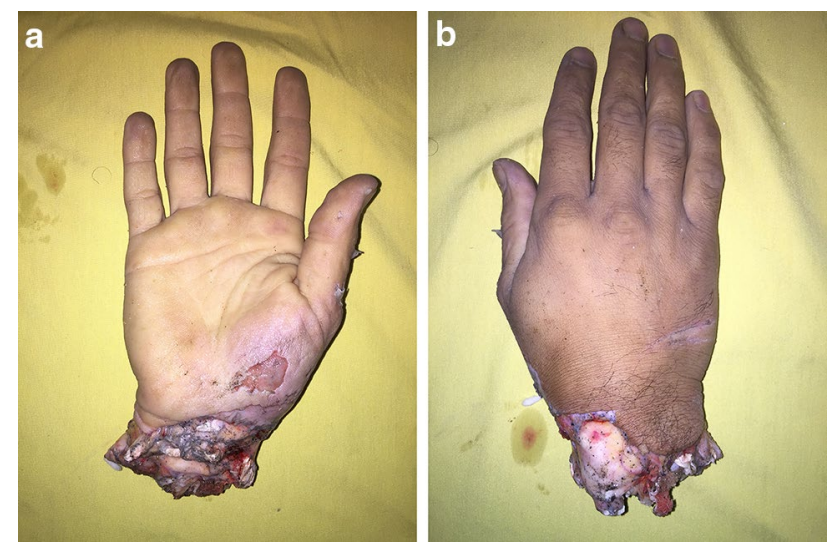

Fig. 1 Pre-op photograph of the amputated wrist volar (a) and dorsal (b)

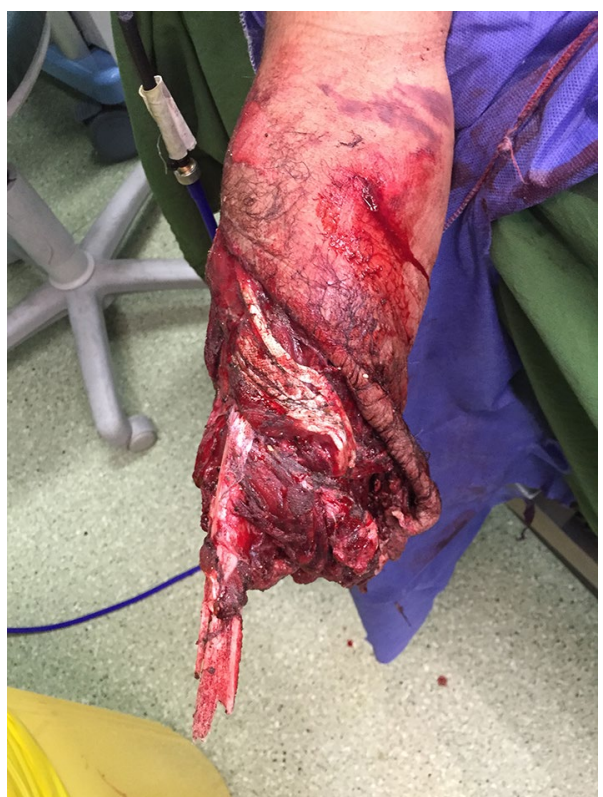

Fig. 2 Proximal amputation stump showing extensive soft tissue and bone loss, as well as heavy contamination

the wrist was replanted over the ulna and fixed with two pins (Fig. 9).

Arterial anastomosis was performed $10 \mathrm{~cm}$ above the amputation level to the proximal ulnar artery. Venous anastomosis was performed $30 \mathrm{~cm}$ above the amputation level to the cephalic vein. Because only volar coverage was possible with remaining skin, saphenous vein was placed at volar aspect (Fig. 10).

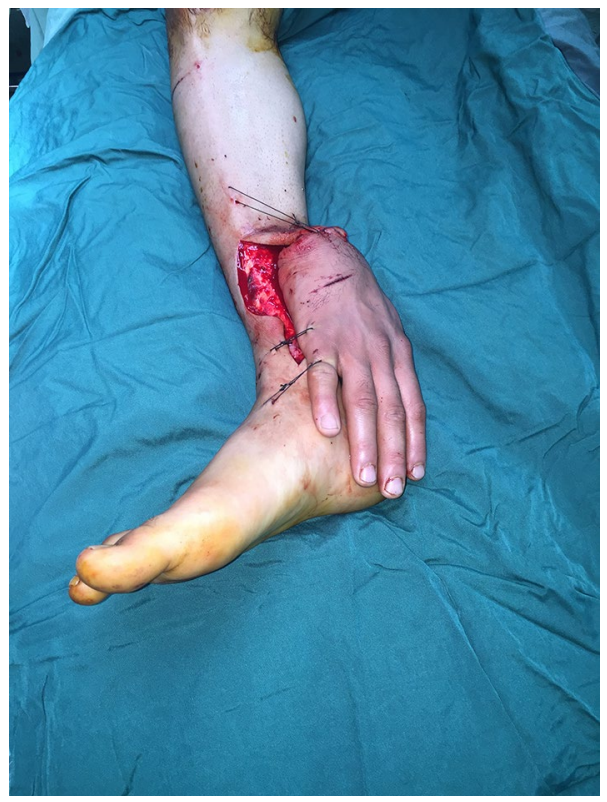

Fig. 3 Banking of the right wrist over the right ankle 


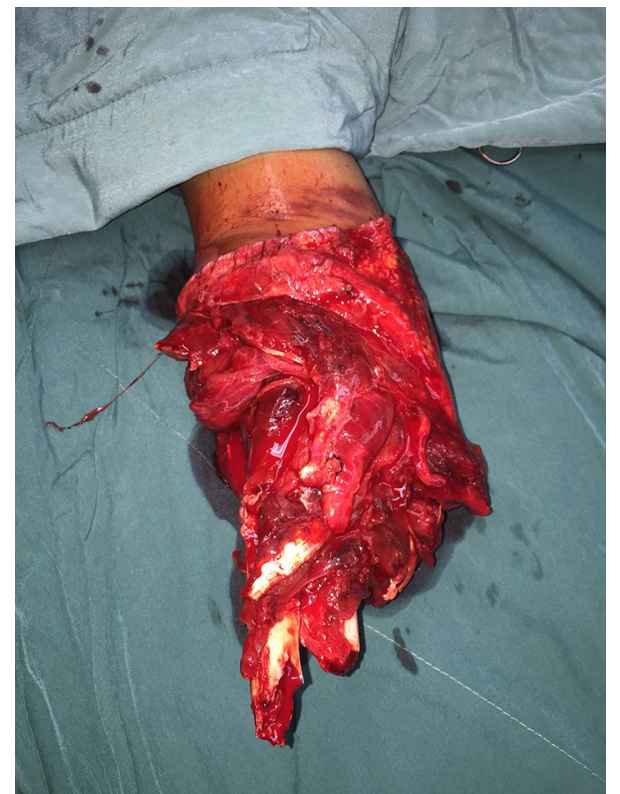

Fig. 4 Proximal forearm stump 8 days after trauma

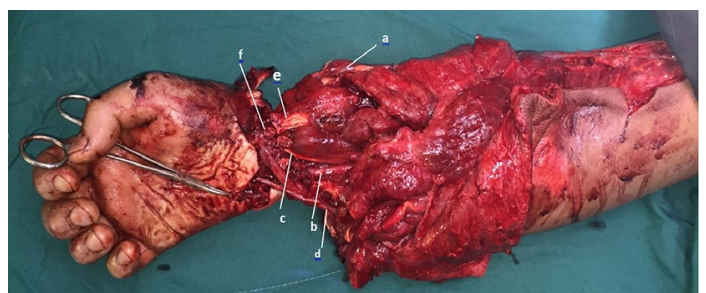

Fig. 5 a Saphenous vein. b Posterior tibialis artery as the intercalary graft. c Ulnar nerve. d Median nerve. e Flexor tendons. f Flexor pollicis longus

The FDPS were transferred side-to-side and repaired to remnants of proximal FDP tendons. The flexor pollicis longus was repaired to the pronator teres. EDC tendons were transferred side-to-side and attached to EDC remnant muscle.

After final debridement, median nerve had $5 \mathrm{~cm}$ gap and ulnar nerve had extra $5 \mathrm{~cm}$ of healthy length. We performed nerve transposition to avoid nerve grafting. Ulnar nerve was transposed to median and median nerve was transposed to the ulnar nerve. Both nerves were rotated $180^{\circ}$ in cooptation to cover the internal sensory-motor fascicle arrangement (Fig. 5).

We covered the volar side with the remaining proximal forearm skin. The saphenous flap was inset again at its original location. Minimal active motion was allowed from the postoperative day.

Six days later, exposed distal dorsal forearm was covered with a groin flap (Fig. 6). After 2 weeks, the groin
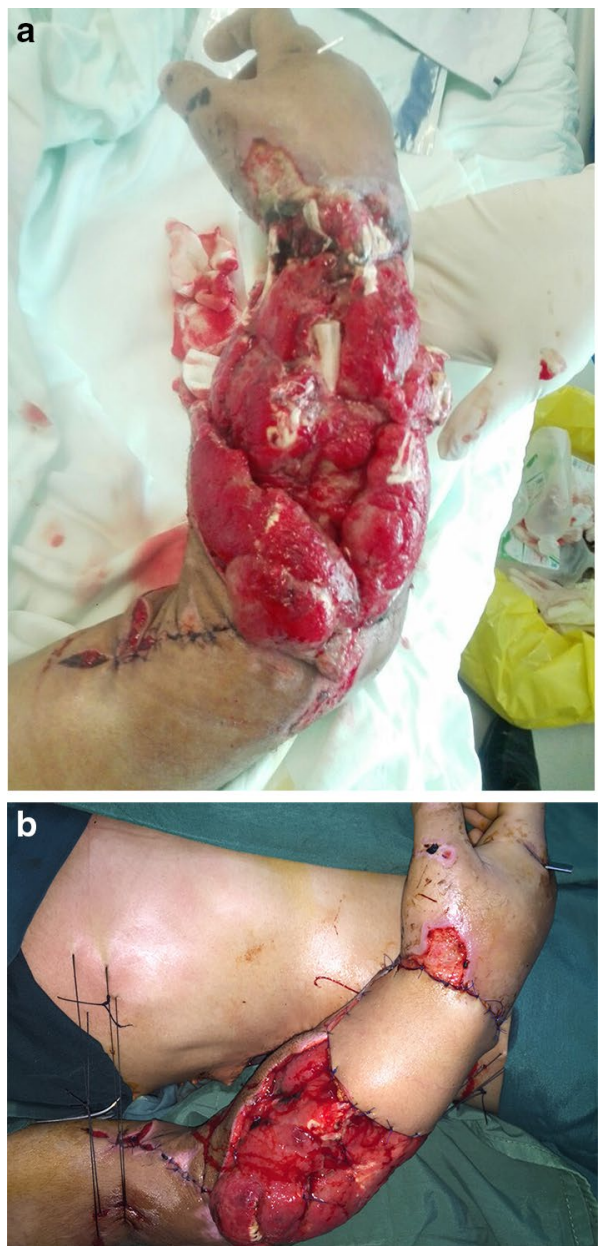

Fig. 6 Wound was uncovered dorsally (a). Groin flap coverage was done for distal area with exposed radius and dorsal tendons (b)

flap pedicle was incised and more proximal dorsal exposed muscle area was covered with split thickness skin graft. Occupational therapy was started 2 weeks after skin grafting when all sutures were removed. Active and passive movements were improved. Eight months after replantation, pins were removed and rigid ulna-lunate fusion and bone grafting was performed (Fig. 9).

The patient was assessed 30 months after replantation; results are reflected in Table 1.

We did not encounter any complications from the anastomoses and no infection developed. The patient had no pain, weakness, or any other complaints from the donor site on the leg by the end of the follow-up. 
Fig. 7 Photography 18 months after replantation. There is

$85 \mathrm{~mm}$ limb length discrepancy
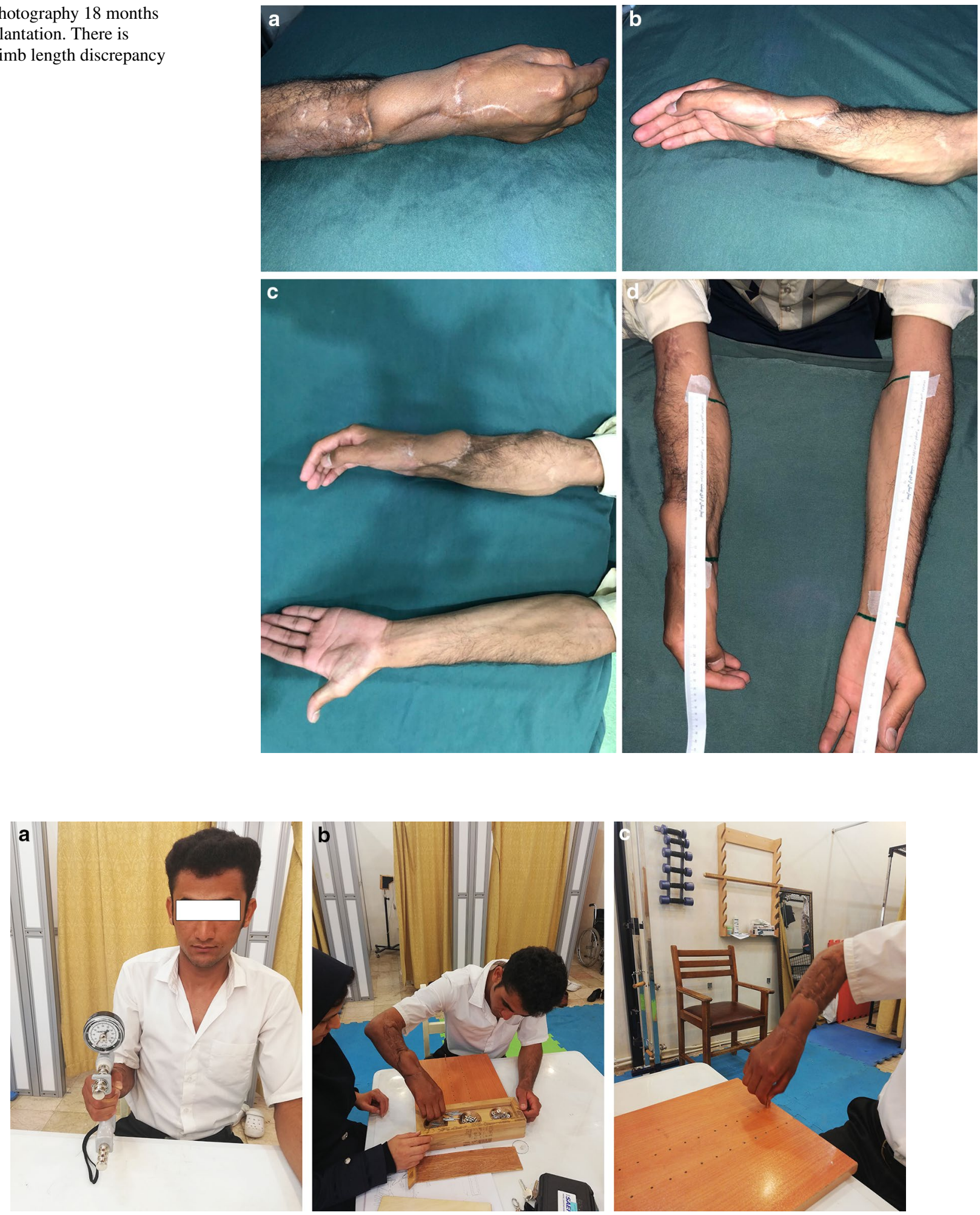

Fig. 8 Patient was assessed by qualified occupational therapist 


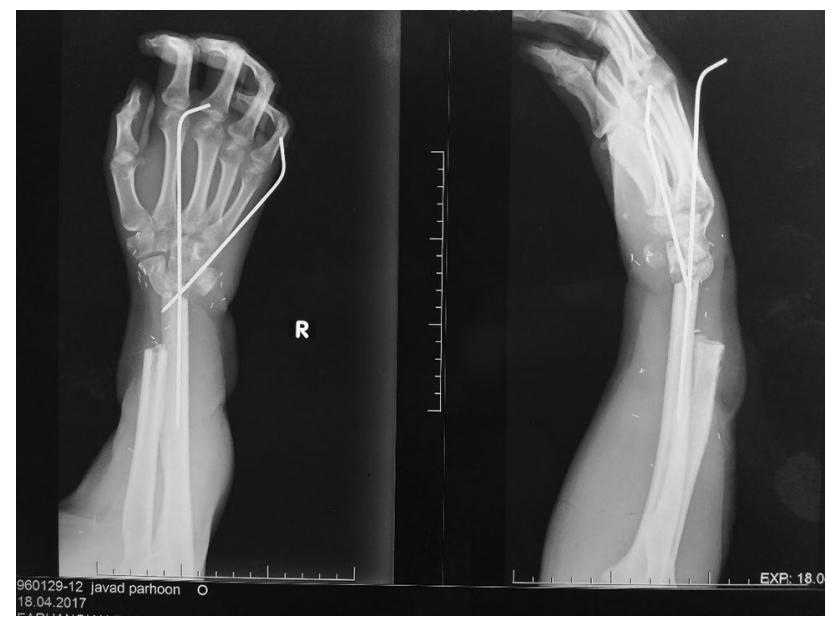

Fig. 9 Provisional pin fixation

\section{Discussion}

Some rare indications have been discussed for ectopic banking: injuries with extensive soft-tissue loss or contamination; extensive vascular injury; and the combination of complex injuries and traumatic shock. These reasons cause a delay in immediate replantation and necessitate banking to resuscitate the viability of the amputated part [11].

Successful implantation surgeries depend on different factors such as the condition of soft tissue and bone, and the ischemia time. Also the surgeon should have a later plan to reconstruct a functional useful limb. Our main incentive to bank the limb in this patient was that the distal part was not injured longitudinally, but the proximal stump was. Also some viable muscles and nerves were available, so that the operation could lead to useful function.
Godina suggested that the thoracodorsal vessels are the most convenient recipient vessels that can match the ulnar and radial arteries [1]. Graf et al. [12] and Kayikcioglu et al. [13] do not suggest the use of the groin or axilla as a banking site. In their opinion, the hip movement is a hindrance for resuscitation of vital structures. Graf has suggested that the forearm is the best choice for a temporary ectopic implantation [12]. Chernofsky and Sauer [13] and Hallock [10] have reported that inferior epigastric vessels are readily accessible.

Posterior tibialis artery, although important to leg, was our choice, because the ipsilateral tibialis anterior pulse was strong and we needed long pedicle arterial and adjacent venous graft. Also we needed to cover the anastomoses temporarily which was possible at this position.

Although the contralateral forearm was another option, it was excluded, because this was the patient's only functioning hand, long straight vein was not available and a local expendable flap for temporary coverage was not present.

In this case, the wrist joint was missing; therefore, carpus was fused to longer stump ulna in $30^{\circ}$ pronation for best functional outcome.

One of the strengths of our method in comparison with Zhang was our long-term follow-up and use of standard tests to evaluate the extremity function. Knowledge of the outcome of the approach can enable researchers and surgeons to make an informed decision about the use of this method.

\section{Conclusion}

Primary planning for later possible reconstructions to achieve a useful limb is the most important step for decision to save an amputated limb. Banking of large amputated limb parts over the leg area can be an acceptable choice to maintain limb circulation during preparing final recipient area. Also, its vascular structure can be used as a long graft

Fig. 10 Final plate fusion

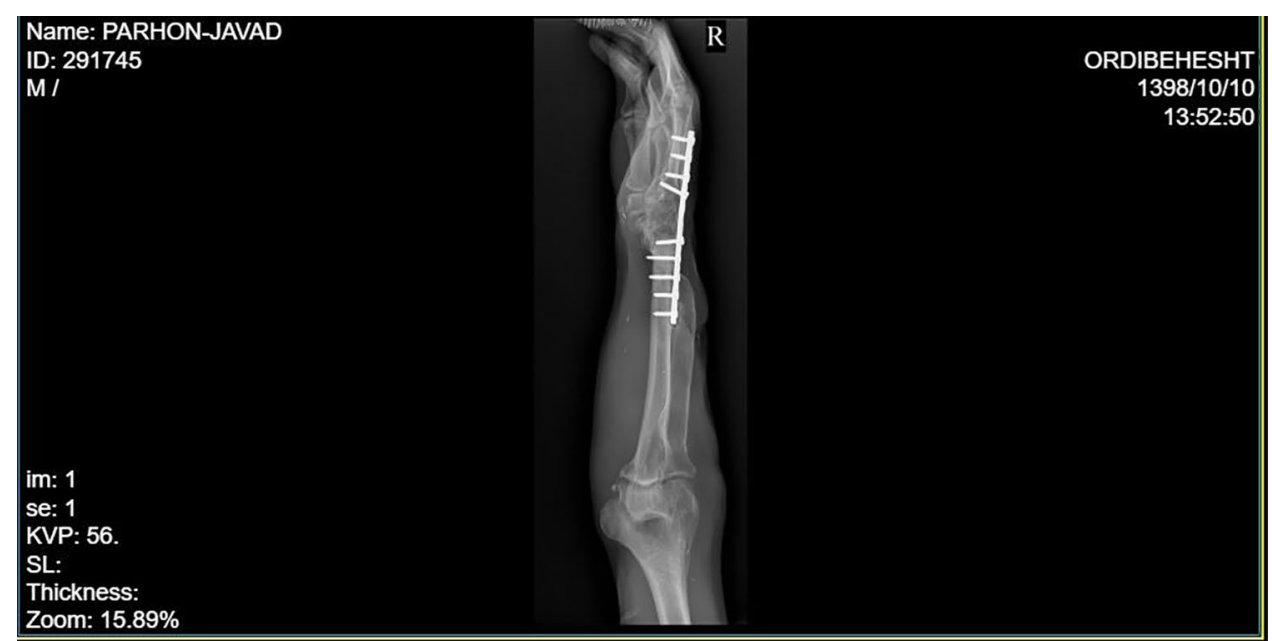


Table 1 Outcome measurements of the transplanted hand as evaluated by the Disabilities of Arm, Shoulder, and Hand (DASH) score

\begin{tabular}{|c|c|c|}
\hline & Right hand & Left hand \\
\hline Box and block (number in $60 \mathrm{~s}$ ) & 25 & 50 \\
\hline Purdue pegboard & $\begin{array}{l}\text { Number in } 30 \mathrm{~s} \text { for } \mathrm{R} \text { hand }(1) \\
\text { Number in } 30 \mathrm{~s} \text { for } \mathrm{L} \text { hand }(10) \\
\text { Number in } 30 \mathrm{~s} \text { for both hand (8) } \\
\text { Asseb, e (2) } \\
\text { Total score (21) }\end{array}$ & \\
\hline Semmes-Weinstein monofilaments & $3 / 61$ (close to normal use of hand) & $2 / 83$ (normal) \\
\hline $2 \mathrm{pd}$ & $\begin{array}{l}\text { Distinguish } 15 \mathrm{~mm} \text { so } \\
\text { Poor } 2 \mathrm{PD} \text { for } 2 \text { radial side fingers } \\
\text { (thumb and index) } \\
\text { Protective sense, able to distinguish } \\
\text { sharp from dull in the ulnar side }\end{array}$ & $\begin{array}{l}\text { Distinguish } 5 \mathrm{~mm} \\
\text { distance in every } \\
\text { zone }\end{array}$ \\
\hline Elbow flexion ROM & $97^{\circ}$ & $130^{\circ}$ \\
\hline Elbow extension & $97^{\circ}$ & $130^{\circ}$ \\
\hline Forearm supination & $0^{\circ}$ & $85^{\circ}$ \\
\hline Forearm pronation & $0^{\circ}$ & $85^{\circ}$ \\
\hline Wrist flexion & $0^{\circ}$ & $80^{\circ}$ \\
\hline Wrist extension & $0^{\circ}$ & $60^{\circ}$ \\
\hline Total active motion of index ( 2 th) & $100^{\circ}$ & $200^{\circ}$ \\
\hline Total active motion of middle finger & $125^{\circ}$ & $185^{\circ}$ \\
\hline Total active motion of ring & $150^{\circ}$ & $180^{\circ}$ \\
\hline Total active motion of 5 th finger & $125^{\circ}$ & $160^{\circ}$ \\
\hline Dynamometer (Pound) & 20 & 70 \\
\hline Pinch gauge (Pound) & 8 & 22 \\
\hline DASH (symptom section) & $35 \%$ & \\
\hline DASH (work item) & $50 \%$ & \\
\hline DASH (music item) & $87.5 \%$ & \\
\hline
\end{tabular}

without any major complications and the saphenous flap is very useful to cover the anastomoses temporarily.

Acknowledgements The authors acknowledge the surgery team of Ordibehesht Hospital in carrying out this work.

\section{Compliance with Ethical Standards}

Conflict of interest The authors report no conflicts of interest. The authors alone are responsible for the content and writing of this article.

Ethical standard statement This study has been approved by the ethics committee of Ordibehesht Hospital, Shiraz, Iran and have therefore been performed in accordance with ethical standards laid down in declaration of Helsinki.

Informed consent Informed consent has been obtained from the patient to publish his photographs and information.

Open Access This article is licensed under a Creative Commons Attribution 4.0 International License, which permits use, sharing, adaptation, distribution and reproduction in any medium or format, as long as you give appropriate credit to the original author(s) and the source, provide a link to the Creative Commons licence, and indicate if changes were made. The images or other third party material in this article are included in the article's Creative Commons licence, unless indicated otherwise in a credit line to the material. If material is not included in the article's Creative Commons licence and your intended use is not permitted by statutory regulation or exceeds the permitted use, you will need to obtain permission directly from the copyright holder. To view a copy of this licence, visit http://creativecommons.org/licenses/ by-nc/4.0/.

\section{References}

1. Godina, M., Bajec, J., \& Baraga, A. (1986). Salvage of the mutilated upper extremity with temporary ectopic implantation of the undamaged part. Plastic and Reconstructive Surgery, 78(3), 295-299.

2. Higgins, J. P. (2011). Ectopic banking of amputated parts: A clinical review. The Journal of Hand Surgery. American Volume, 36(11), 1868-1876.

3. Valerio, I. L., Hui-Chou, H. G., Zelken, J., Basile, P. L., Ipsen, D., \& Higgins, J. P. (2014). Ectopic banking of amputated great toe for delayed thumb reconstruction: Case report. The Journal of Hand Surgery. American Volume, 39(7), 1323-1326.

4. Cavadas, P. C., Landín, L., \& Ibáñez, J. (2009). Temporary catheter perfusion and artery-last sequence of repair in macroreplantations. Journal of Plastic, Reconstructive \& Aesthetic Surgery, 62(10), 1321-1325.

5. Chernofsky, M. A., \& Sauer, P. F. (1990). Temporary ectopic implantation. The Journal of Hand Surgery. American Volume, 15(6), 910-914. 
6. Jennings, J. F., Murphy, R. X., Jr., Chernofsky, M. A., \& Chowdary, R. P. (1991). Amputation stump salvage using a "banked" free-tissue transfer. Annals of Plastic Surgery, 27, 361-363.

7. Kayikçioğlu, A., Ağaoğlu, G., Nasir, S., \& Keçik, A. (2000). Crossover replantation and fillet flap coverage of the stump after ectopic implantation: A case of bilateral leg amputation. Plastic and Reconstructive Surgery, 106(4), 868-873.

8. Wang, J. N., Tong, Z. H., Zhang, T. H., Wang, S. Y., Zhang, H. Q., Zhao, G. Q., et al. (2006). Salvage of amputated upper extremities with temporary ectopic implantation followed by replantation at a second stage. Journal of Reconstructive Microsurgery, 22(1), 15-20.

9. Zhang, X., \& Zhu, H. W. (2015). Temporary ectopic hand implantation. Plastic and Aesthetic Research, 2(1), 43-46.

10. Hallock, G. G. (1992). Transient single-digit ectopic implantation. Journal of Reconstructive Microsurgery, 8(4), 309-311.
11. Nazerani, S., Vaseghi, H., Hesami, S., \& Nazerani, T. (2013). Ectopic major transplantation for salvage of upper and lower extremity amputations. Chinese Journal of Traumatology, 16(6), 330-333.

12. Graf, P., Groner, R., \& Horl, W. (1996). Temporary ectopic implantation for salvage of amputated digits. British Journal of Plastic Surgery, 49(3), 174-177.

13. Chernofsky, M. A., \& Sauer, P. F. (1990). Temporary ectopic implantation. Journal of Hand Surgery. American Volume, 15, 910-914.

Publisher's Note Springer Nature remains neutral with regard to jurisdictional claims in published maps and institutional affiliations. 